\title{
Prevalence, diagnosis, and treatment of familial hypercholesterolaemia in outpatient practices in Poland
}

\author{
Krzysztof Chlebus ${ }^{1}$, Barbara Cybulska ${ }^{2}$, Marcin Gruchała ${ }^{1}$, Anna Smaga ${ }^{3}$, Katarzyna Wróbel ${ }^{3}$, \\ Bogdan Wojtyniak ${ }^{4}$, Marcin Pajkowski ${ }^{1}$, Piotr Jankowski ${ }^{5}$, Tomasz Zdrojewski ${ }^{6}$ \\ ${ }^{1} 1^{\text {st }}$ Department of Cardiology, Medical University of Gdansk, Gdansk, Poland \\ ${ }^{2}$ National Food and Nutrition Institute, Warsaw, Poland \\ 3PEX PharmaSequence Sp. z o.o., Warsaw, Poland \\ ${ }^{4}$ National Institute of Public Health - National Institute of Hygiene (NIPH - NIH), Warsaw, Poland \\ ${ }^{5} 1^{\text {st }}$ Department of Cardiology and Arterial Hypertension, Institute of Cardiology, Jagiellonian University, Medical College, Krakow, Poland \\ ${ }^{6}$ Department of Preventive Medicine and Education, Gdansk, Poland
}

\begin{abstract}
A bstract
Background: Familial hypercholesterolaemia $(\mathrm{FH})$ is the most common genetic disease leading to premature atherosclerosis. Aim: The aim of the study was to evaluate the prevalence, diagnosis, and treatment of FH in outpatient practices in Poland. Methods: The study included a representative sample of 147 primary care physicians, cardiologists, and diabetologists caring for 2812 adult patients with hypercholesterolaemia and low-density lipoprotein cholesterol (LDL-C) level $>1.8 \mathrm{mmol} / \mathrm{L}$, who were treated with statins or did not receive statins due to intolerance or contraindications. The physicians declared whether they diagnosed FH in the study group. In addition, we evaluated the Dutch Lipid Clinic Network (DLCN) diagnostic criteria for $\mathrm{FH}$ in all patients. The results were weighted and extrapolated to the general outpatient population in Poland. Treatment and its effectiveness were also evaluated.

Results: FH6 + score by the DLCN criteria was found in $3.6 \%$ of the study group, which translates by extrapolation to 136,300 adult patients with FH in Poland. Among patients with $\mathrm{FH} 6+$, this diagnosis was correctly made by physicians in $25 \%$ of cases and was not established in $75 \%$ of cases. Only $32.8 \%$ of patients received high statin doses. High LDL-C levels were found in a large proportion of patients, including levels $\geq 5.0 \mathrm{mmol} / \mathrm{L}$ in $42.7 \%$ of patients and $\geq 4.1 \mathrm{mmol} / \mathrm{L}$ in $59.7 \%$ of patients.

Conclusions: Familial hypercholesterolaemia is inadequately diagnosed and treated in Poland, which calls for a radical improvement of pre- and postgraduate education in this regard.
\end{abstract}

Key words: familial hypercholesterolaemia, epidemiology, outpatient practice, survey

Kardiol Pol 2018; 76, 6: 960-967

\section{INTRODUCTION}

Familial hypercholesterolaemia (FH) is the most common genetic disease in the general population, occurring mostly in the heterozygotic form (heterozygotic familial hypercholesterolaemia, $\mathrm{HeFH}$ ). The prevalence of $\mathrm{FH}$ in Poland has been estimated at one in 250 adults [1]. High levels of low-density lipoprotein cholesterol (LDL-C) since early life are associated with premature ischaemic heart disease $[2,3]$. The hetero- zygotic form, usually inherited from one parent, is mostly caused by a mutation in the LDL receptor gene. Less frequent causes include apolipoprotein B (apo B) gene mutations, and even less frequent are proprotein convertase subtilisin/kexin type 9 (PCSK9) gene mutations. For a long time, $\mathrm{FH}$ has not gained interest among clinicians despite risks of premature myocardial infarction and death, as indicated by the title of the European Atherosclerosis Society expert panel publica- 
tion, "Familial hypercholesterolaemia is underdiagnosed and undertreated in the general population" [3]. It resulted from a mistaken belief (based on previous studies) that the disease was relatively infrequent, the inability to diagnose it, and the lack of available therapeutic options to reduce high LDL-C levels to low values that are associated with a lower risk for coronary artery disease. Currently, new potent lipid-lowering agents combined with statins allow LDL-C level reduction to, or close to, the target values in patients with $\mathrm{FH}$ [4-6]. This has prompted more interest in the diagnosis and treatment of this disease and resulted in the publication of multiple management guidelines and expert consensus statements [2, 3, 7-10].

It is now possible to achieve low LDL-C levels that have been proposed in the European guidelines for the management of dyslipidaemia as the therapeutic goals in $\mathrm{FH}$, i.e. LDL-C level $<2.6 \mathrm{mmol} / \mathrm{L}(100 \mathrm{mg} / \mathrm{dL})$ in subjects without cardiovascular disease (CVD) and $<1.8 \mathrm{mmol} / \mathrm{L}(70 \mathrm{mg} / \mathrm{dL}$ ) in those with CVD [8]. Thus, the pathway to improve the diagnosis and management of $\mathrm{FH}$ might appropriately begin with an improved knowledge on the current status of outpatient care of this condition in Poland.

The aim of the Economedica Dyslipidaemia 2015 study was to evaluate the prevalence and quality of the diagnosis and treatment of at least probable $\mathrm{FH}$ in outpatient care in Poland, based on a representative sample of physicians (primary care physicians, cardiologists, and diabetologists) and their patients. Our study design allowed: (i) estimation of the size of the adult $\mathrm{FH}$ patient population under outpatient care in Poland; and (ii) extrapolation of our findings regarding the diagnosis and treatment of $\mathrm{FH}$ to that population.

\section{METHODS}

\section{Physician sampling}

Physician sampling was based on 12 strata (six geographical regions, overall 2-4 voivodeships, according to the classification by the Central Statistical Office of Poland, and two types of locations based on the physician's place of work — voivodeship capital cities and other locations), taking into account the structure of selected physician specialties in the Health Data Management database (https://www.farmaprom. $\mathrm{pl} / \mathrm{pl} / \mathrm{bazy}$-danych/). To obtain adequate precision of study findings among specialists, we intentionally increased the number of invited cardiologists and diabetologists in relation to primary care physicians, with compensation by appropriate weighting during further analyses. Physician recruitment for the study was based on quota sampling. We invited 75 primary care physicians, 45 cardiologists, and 30 diabetologists to participate in the study. Overall, 147 physicians agreed to participate, including 72 primary care physicians, 45 cardiologists, and 30 diabetologists. Primary care physicians could be recruited for the study if they saw at least 100 patients, and cardiologists and diabetologists were considered if they saw at least 60 patients during a typical workweek.

\section{Patient sampling}

The study was conducted from June to August 2015. Each participating physician recorded all adult patients (aged $\geq 18$ years) seen within two weeks and identified those with hypercholesterolaemia with LDL-C level > $1.8 \mathrm{mmol} / \mathrm{L}(70 \mathrm{mg} / \mathrm{dL})$, including patients treated with statins for at least six months, those who were prescribed with statins at the current visit, and those who were not treated with statins due to intolerance or contraindications. A questionnaire consisting of two parts, $A$ and $B$, was filled in for the first 20 patients.

Part A of the questionnaire, "Patient characteristics and treatment," included, among others, data on patient age, sex, serum lipid profile (total cholesterol, LDL-C, HDL-C, and triglyceride levels), including the most recent one and the one before initiation of lipid-lowering therapy, use of lipid-lowering drugs and their doses, and concomitant conditions including CVD and the date of the last cardiovascular event. Thus, the questionnaire included two items that might have indicated probable or definite $\mathrm{FH}$, i.e. pre-treatment LDL-C level and premature occurrence of coronary artery disease or other CVD.

Part B of the questionnaire included information about the Dutch Lipid Clinic Network (DLCN) diagnostic criteria for $\mathrm{FH}[2,3]$, without actual scoring as per the DLCN score.

Data were collected using the Computer Assisted Web Interview (CAWI) technique using an Internet form created for the project. A paper form of the questionnaire was used if there was no computer access. Patient data were coded before being sent to the study administrator, without any possibility to decode them.

Based on the answers to the questions in part $\mathrm{A}$ of the questionnaire, physicians declared whether $\mathrm{FH}$ was diagnosed in patients and identified the specialty of the physician who made the diagnosis. By filling in part B of the questionnaire, they also independently provided data on the presence or absence of the DLCN diagnostic criteria. Based on the latter information, we were able to perform DCLN scoring and identify patients with a definite (score $>8$ ) or a probable (score 6-8) diagnosis of $\mathrm{FH}$.

\section{Study material}

During the study period, the participating physicians saw on average 32 patients per day, and within the working days of the two-week span covered they saw an average of 11 patients per day who had indications for lipid-lowering treatment for hypercholesterolaemia. Overall, data were collected for 2812 patients, including 1349 patients seen by primary care physicians, 884 patients seen by cardiologists, and 579 patients seen by diabetologists. Due to a server failure, part B of the questionnaire was filled in for 2257 patients, including 1049 patients seen by primary care physicians, 696 patients seen by cardiologists, and 512 patients seen by diabetologists. 


\section{Weighting and extrapolation}

The number of patients presenting separately to primary care physicians, cardiologists, and diabetologists was appraised based on the length of the periods between visits, as calculated from the number of days for which the therapy was prescribed. The duration of prescribed treatment was calculated based on the daily drug dose and the number of drug packages prescribed. Because the study recruited more cardiologists and diabetologists than would be appropriate based on the nationwide ratio of cardiologists and diabetologists to primary care physicians, we performed physician post-stratification by applying weights to correct the proportion of primary care physicians to cardiologists and diabetologists, making it similar to the ratio between these specialties in Poland, which is 21:3.4:1 (primary care physicians, cardiologists, and diabetologists, respectively). During the weighting and extrapolation process, we additionally corrected the age structure of the study patients based on the data from the RECEPTOmetr Sequence (a commercial continuous data tool for monitoring prescriptions). After evaluating of the number of patients presenting to primary care physicians, cardiologists, and diabetologists, and weighting the results in accordance with the current proportions between primary care physicians and specialists, we estimated the number of adult patients receiving outpatient care from the studied physician specialties, the number of patients with hypercholesterolaemia, and the number of patients with $\mathrm{FH}$.

All results presented below are weighted and extrapolated to the general population.

\section{Statistical analysis}

Statistical analysis was performed using SPSS v. 21.0 (SPSS Inc., Chicago, IL, USA) software. To compare the frequency of feature occurrence $\chi^{2}$ test was carried out, and to compare average values the $t$ test for equality of means was performed. When defining statistical significance, a value of $\mathrm{p}<0.05$ (confidence level 0.95) was adopted.

\section{RESULTS}

Following the weighting and extrapolation process, our study findings indicate that the number of adult patients in Poland with LDL-C levels $>1.8 \mathrm{mmol} / \mathrm{L}$ and indications for lipid-lowering therapy, who receive outpatient care (primary care physicians, cardiologists, and diabetologists) can be estimated at 3,757,546.

Among 2812 outpatients with LDL-C levels $>1.8 \mathrm{mmol} / \mathrm{L}$, who were seen by the study physicians, the criteria of definite or probable $\mathrm{FH}$ (DLCN score of $\geq 6[\mathrm{FH} 6+]$ ) were met by 95 subjects (49 were reported by primary care physicians, 36 by cardiologists, and 10 by diabetologists). This amounted to $3.6 \%$ of the study group, and when extrapolated to the general population our findings indicate that the overall num- ber of adult outpatients with $\mathrm{FH}$ in Poland can be estimated at 136,300 .

The criteria of definite $\mathrm{FH}$ (DLCN score of $>8$ ) were met by 51 subjects. By extrapolation to the general population, this number translates to $2.2 \%$, which means 80,800 adult outpatients in Poland.

Out of 95 patients with six or more points on a scale of DLCN, 37 were treated with high doses of statins, 63 were treated in secondary prevention (at least one of the following: unstable coronary artery disease, myocardial infarction [STEMI/NSTEMI], ischaemic stroke/transient ischaemic attack, coronary revascularisation [CABG/PTCA], ischaemic heart disease/stable coronary artery disease, peripheral arterial disease), and 31 of them were treated with high statin doses.

Notable characteristics of patients with at least probable FH compared to patients with previously established hypercholesterolaemia (without FH) with LDL-C level of $>1.8 \mathrm{mmol} / \mathrm{L}$ included significantly younger age $(57.1$ years vs. 64.9 years) and significantly higher mean total cholesterol and LDL-C levels $(6.24 \mathrm{mmol} / \mathrm{L}$ [241.4 mg/dL] vs. $5.17 \mathrm{mmol} / \mathrm{L}$ [200.3 mg/dL] and $4.54 \mathrm{mmol} / \mathrm{L}[175.4 \mathrm{mg} / \mathrm{dL}]$ vs. $2.99 \mathrm{mmol} / \mathrm{L}$ [115.5 mg/dL], respectively). These data are shown in Table 1 .

We also found different rates of diabetes $(24.6 \%$ vs. $34.0 \%$ ) and hypertension ( $77.5 \%$ vs. $86.5 \%$ ) between patients with $\mathrm{FH} 6+$ and the remaining patients. In contrast, no clear differences (without standardisation for age) were seen in the rates of CVD.

Following age standardisation, CVD was significantly more prevalent $(\mathrm{p}<0.05)$ in patients with $\mathrm{FH} 6+(61.9 \%)$ compared to the remaining patients $(49.1 \%)$. Significantly higher total cholesterol and LDL-C levels in patients with $\mathrm{FH} 6+$ were seen also after age standardisation, while the differences in the rates of other concomitant conditions, i.e. type 2 diabetes and hypertension, were reduced.

In the group of patients with LDL-C levels $>1.8 \mathrm{mmol} / \mathrm{L}$ and at least probable $\mathrm{FH}, 85 \%$ of patients, after weighting and extrapolation, received statin therapy, but less than half of them $(46.5 \%)$ received high statin doses, i.e. rosuvastatin $\geq 20 \mathrm{mg} /$ day or atorvastatin $\geq 40 \mathrm{mg} /$ day. When extrapolating these data to the general population, as described above (3.6\% of the study group, translating to 136,000 patients with at least probable $\mathrm{FH}$ in the general population), it may be estimated that 116,000 (85.3\%) patients receive statin therapy, of which 54,000 patients receive high statin doses. It should also be noted that 13,000 (9.6\%) patients in this group do not receive statin therapy due to intolerance or contraindications.

Among patients with $\mathrm{FH} 6+$ and LDL-C levels $>1.8 \mathrm{mmol} / \mathrm{L}$ during intensive statin therapy, LDL-C level was $\geq 2.6 \mathrm{mmol} / \mathrm{L}$ $(100 \mathrm{mg} / \mathrm{dL}$ ) in $88.3 \%$ of patients, $\geq 4.1 \mathrm{mmol} / \mathrm{L}$ in $59.7 \%$ of patients, and $\geq 5.0 \mathrm{mmol} / \mathrm{L}$ in $42.7 \%$ of patients receiving high doses of potent statins, when extrapolated to the general Polish population. It translates to $47,705,31,944$ and 23,357 patients with $\mathrm{FH}$, respectively (Fig. 1). 
Table 1. Patients' characteristics

\begin{tabular}{lccc|} 
Patient profile & FH6+ & $\begin{array}{c}\text { FH6+ after standardisation } \\
\text { for age in FH6+ group }\end{array}$ & $\begin{array}{c}\text { Remaining patients } \\
\text { (LDL-C > 1.81 mmol/L)* }\end{array}$ \\
\hline Unweighted sample size & $\mathrm{n}=95$ & $\mathrm{n}=95$ & $\mathrm{n}=2162$ \\
Age [years] & $57.1 \pm 11.6$ & $64.5 \pm 10.9$ & $64.9 \pm 11.1$ \\
Body mass index $\left[\mathrm{kg} / \mathrm{m}^{2}\right]$ & $29.4 \pm 4.3$ & $29.1 \pm 4.3$ & $28.2 \pm 4.1$ \\
Total cholesterol $[\mathrm{mmol} / \mathrm{L}]$ & $6.24 \pm 1.48$ & $6.18 \pm 1.53$ & $5.18 \pm 1.04$ \\
Triglycerides $[\mathrm{mmol} / \mathrm{L}]$ & $2.05 \pm 0.85$ & $1.99 \pm 0.91$ & $1.61 \pm 0.74$ \\
LDL-C $[\mathrm{mmol} / \mathrm{L}]$ & $4.54 \pm 1.66$ & $4.29 \pm 1.58$ & $2.99 \pm 0.89$ \\
Men & $64.6 \%(88,000)$ & $58.2 \%(79,000)$ & $46.3 \%(1,676,000)$ \\
Type 2 diabetes & $24.6 \%(34,000)$ & $33.6 \%(46,000)$ & $34.0 \%(1,230,000)$ \\
Hypertension & $77.5 \%(106,000)$ & $83.1 \%(113)$ & $86.5 \%(3,131,000)$ \\
Chronic kidney disease & $4.0 \%(6000)$ & $5.4 \%(7000)$ & $7.7 \%(279,000)$ \\
Smokers in recent quartiles $(<3$ months) & $26.4 \%(36,000)$ & $27.2 \%(37,000)$ & $24.4 \%(885,000)$ \\
Cardiovascular disease** & $49.4 \%(67,000)$ & $61.9 \%(84,000)$ & $49.1 \%(1,776,000)$ \\
\hline
\end{tabular}

Data are shown as mean \pm standard deviation or percentage (number). LDL-C - low-density lipoprotein cholesterol Patient numbers rounded according to the rule of rounding to the nearest thousand.

* Remaining patients - those with Dutch Lipid Clinic Network score (DLCN) $<6$.

**At least one of the following: ischaemic heart disease, myocardial infarction (STEMI/NSTEMI), unstable coronary artery disease, previous ischaemic stroke/transient ischaemic attack, coronary revascularisation (CABG/PTCA), peripheral arterial revascularisation, peripheral amputation due to atherosclerotic vascular disease.

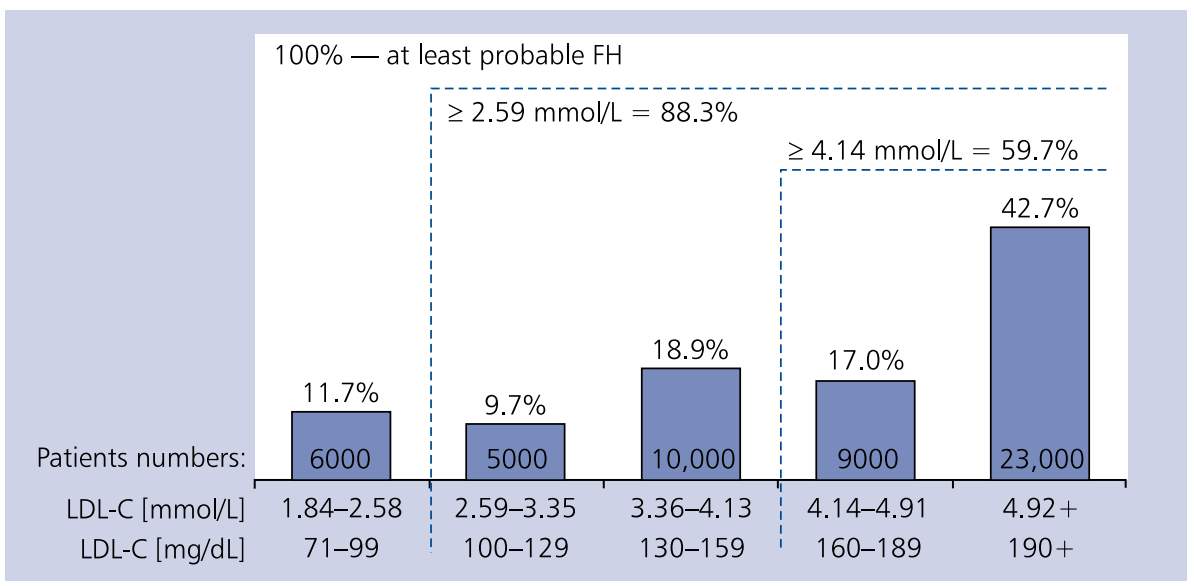

Figure 1. Distribution of low-density lipoprotein cholesterol (LDL-C) levels (\% of patients) in patients with FH6+ treated with high-dose statins. Extrapolation of study results to the population of patients with familial hypercholesterolaemia (FH) in Poland

Among patients with at least probable $\mathrm{FH}$, after weighting and extrapolation, more than half $(52.5 \%)$ are in secondary prevention, translating to 71,000 patients in the general Polish population. Unfortunately, our findings indicate that only three-fourths of them (about 53,000 patients or $74.8 \%$ ) receive statin therapy, and again only three-fourths of them $(40,000$ patients or $74.3 \%)$ receive high statin doses.

Among secondary prevention patients with $\mathrm{FH} 6+$ and LDL-C levels $>1.8 \mathrm{mmol} / \mathrm{L}$ during intensive statin therapy, after weighting and extrapolation, LDL-C level was $\geq 2.6 \mathrm{mmol} / \mathrm{L}$ in $85.7 \%$ (34,060 patients), $\geq 4.1 \mathrm{mmol} / \mathrm{L}$ in $52.5 \%$ (20,780 patients), and $\geq 5.0 \mathrm{mmol} / \mathrm{L}$ in $43.6 \%$ $(17,540$ patients) of patients despite use of high statin doses (all extrapolated to the general Polish population) (Fig. 2).

In light of the above findings, we also obtained interesting data in regard to drug prescription patterns during visits in the study period. Despite a high likelihood of $\mathrm{FH}$, a low statin dose was prescribed to as many as $45.1 \%$ of patients, significantly less frequently by cardiologists (15.2\% of patients) compared to primary care physicians (56.2\% of patients). Cardiologists 


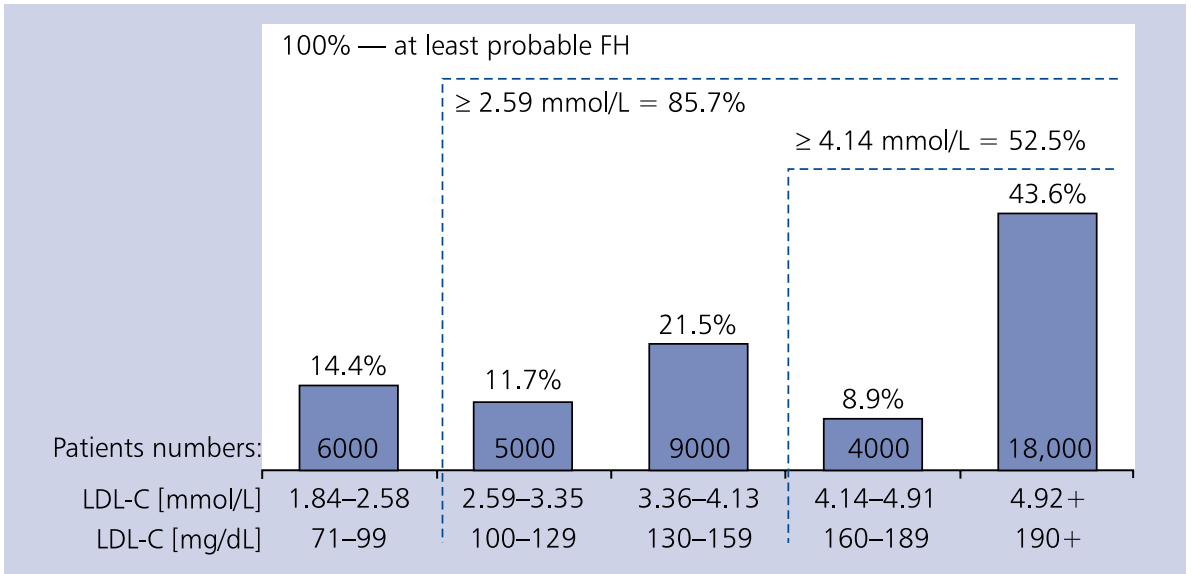

Figure 2. Distribution of low-density lipoprotein cholesterol (LDL-C) levels (\% of patients) in patients with FH6+ (secondary prevention) with LDL-C levels $>1.8 \mathrm{mmol} / \mathrm{L}$ treated with high-dose statins. Extrapolation of study results to the population of patients with familial hypercholesterolaemia (FH) in Poland

Table 2. Lipid-lowering therapy prescribed during the study visit in patients with FH6+ (primary care physicians vs. cardiologists)

\begin{tabular}{lccc} 
& \multicolumn{2}{c}{ Per cent of patients } \\
\cline { 2 - 4 } & Overall & Primary care & Cardiologists \\
\hline Low statin dose & $45.1 \%$ & $56.2 \%$ & $15.2 \%$ \\
High statin dose & $32.8 \%$ & $22.9 \%$ & $59.2 \%$ \\
Low statin dose + ezetimibe & $0.6 \%$ & $0.0 \%$ & $2.8 \%$ \\
High statin dose + ezetimibe & $6.8 \%$ & $6.8 \%$ & $6.4 \%$ \\
Ezetimibe without statin & $0.0 \%$ & $0.0 \%$ & $0.0 \%$ \\
Other treatment & $5.1 \%$ & $5.9 \%$ & $0.0 \%$ \\
No drug therapy & $9.6 \%$ & $8.1 \%$ & $16.4 \%$ \\
Overall & $100 \%$ & $100 \%$ & $100 \%$ \\
\hline
\end{tabular}

High statin dose: rosuvastatin $\geq 20 \mathrm{mg}$ or atorvastatin $\geq 40 \mathrm{mg}$

prescribed high statin doses to $59.2 \%$ of patients with $\mathrm{FH} 6+$, compared to only $22.9 \%$ of such patients seen by primary care physicians. Overall, high statin doses were prescribed to $32.8 \%$ of patients with $\mathrm{FH} 6+$. Other therapies, such as ezetimibe combined with statins or ezetimibe monotherapy, were used in a minority of patients, probably due to the high cost of such treatment in the study period (Table 2).

We also analysed diagnoses of $\mathrm{FH}$ declared by the study physicians. Based on the previous assumptions of about $3,757,546$ adult outpatients with LDL-C levels $>1.8 \mathrm{mmol} / \mathrm{L}$ in Poland, the diagnosis of $\mathrm{FH}$ was declared in about $2.3 \%$ of study patients, which translates to 88,000 patients in Poland. However, an independent objective assessment based on the diagnostic criteria for $\mathrm{FH}$ confirmed this diagnosis in only a subset of these patients, which may be extrapolated to 34,000 patients in the general population. False positive diagnoses of $\mathrm{FH}$ by the study physicians, made in $61 \%$ of patients in whom the diagnosis of $\mathrm{FH}$ was declared by the study physicians, translate to 54,000 patients in the general population. In contrast, among patients without a diagnosis of $\mathrm{FH}$ as declared by the study physicians, translating to $3,349,000$ patients in the general population, the diagnosis of $\mathrm{FH}$ by the DLCN criteria was made in $2.7 \%$ of patients, translating to 90,400 patients in the general population. $\mathrm{FH}$ was also diagnosed in $3.6 \%$ of patients (translating to 320,000 patients in the general population) who were reported by the study physicians as not evaluable due to lack of data, which translates to 11,500 patients in the general population. Overall, this gives 102,000 patients with undiagnosed $\mathrm{FH}$ in the general population, despite the fact that availability of data from personal history, physical examination, family history, and lipid profile testing made this diagnosis feasible and justified (Fig. 3).

Among patients with at least probable $\mathrm{FH}$ based on the DLCN criteria, the diagnosis of $\mathrm{FH}$ was declared by the study physicians in only $25 \%$ of cases (including in $25 \%$ of patients 


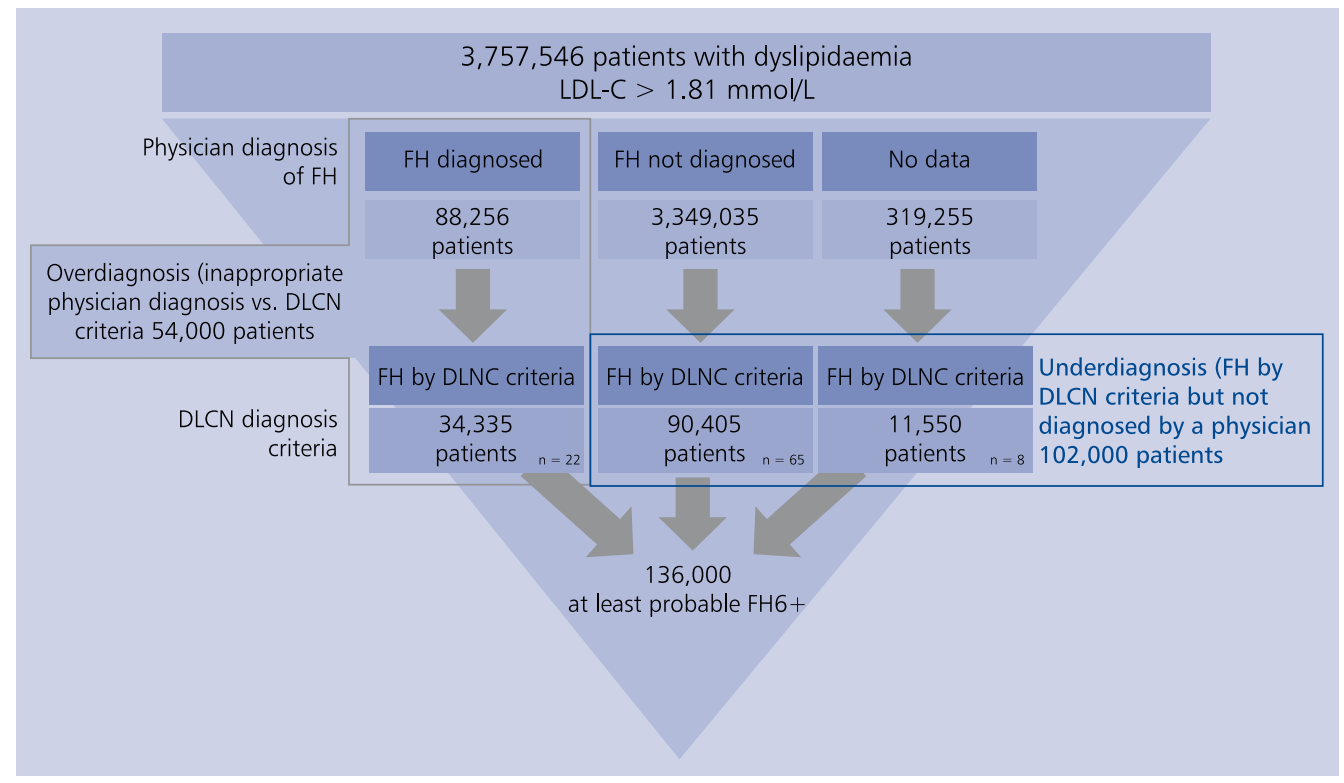

Figure 3. Appropriateness of the diagnosis of familial hypercholesterolaemia $(\mathrm{FH})$ by the study physicians. Extrapolation of the study findings to the population of patients with low-density lipoprotein cholesterol (LDL-C) levels > $1.81 \mathrm{mmol} / \mathrm{L} ; \mathrm{DLCN}-$ Dutch Lipid Clinic Network

cared for by primary care physicians and only $18 \%$ of patients cared for by cardiologists).

\section{DISCUSSION}

In our study, based on a representative sample of physicians (primary care physicians, cardiologists, and diabetologists) and their patients, we received data describing the population of at least probable $\mathrm{FH}$ in outpatient care. Estimation of these results shows the quality of the diagnosis and treatment of at least probable $\mathrm{FH}$ in all outpatient care in Poland.

The first data on the prevalence of $\mathrm{FH}$ in the Polish population were reported in 2016 with the publication of a meta-analysis of six large observational studies that included 37,889 subjects aged between 20 and 79 years [1]. The diagnosis of definite or probable FH was based on the DLCN criteria. The prevalence of at least probable $\mathrm{FH}$ (score $\geq 6$ ) was estimated at 404/100,000 subjects or 0.40\% (approximately $1 / 250$ ), and was similar to the prevalence in other European countries [11-13]. In our study, we estimated that definite or probable $\mathrm{FH}$ may be present in 136,300 adult patients receiving outpatient care. Our results are similar to the findings from the meta-analysis by Pająk et al. [1], although the latter are for the general adult population, and our estimates are for adult outpatients. Definite FH (DLCN score $>8$ ) was identified in seven cases in the meta-analysis, while we found 51 patients with definite $\mathrm{FH}$ based on DLCN scoring, amounting to $2.2 \%$ of the study subjects and translating to about 80,800 adult outpatients cared for by primary care physicians, cardiologists, and diabetologists in Poland. This difference in the rates of definite $\mathrm{FH}$ may be related to the fact that as many as half of our patients had coronary artery disease, and in some of them it was related to severe $\mathrm{FH}(\mathrm{DLCN}$ score $>8)$.

Notably, a high rate of probable or definite $\mathrm{FH}$ was found in Polish patients following an acute coronary syndrome in the EUROASPIRE IV study [14]. FH was present in $11.4 \%$ of the Polish study participants, compared to $8.3 \%$ of patients in the overall EUROASPIRE IV study population (7044 patients from 24 countries aged 18-80 years), including 20.8\% of patients below 50 years of age. These findings indicate a need for the diagnosis of $\mathrm{FH}$ (based on the DLCN criteria) among patients with premature coronary artery disease and LDL-C levels $\geq 4.9 \mathrm{mmol} / \mathrm{L}$ (190 mg/dL) admitted to cardiology units due to an acute coronary syndrome. Regarding treatment of $\mathrm{FH}$, no country-specific data were provided in that publication, but overall $55 \%$ of patients with $\mathrm{FH}$ received intensive statin therapy.

In addition to estimating the prevalence of $\mathrm{FH}$ among outpatients, the other major goal of our study was to evaluate the quality of the diagnosis and treatment of $\mathrm{FH}$. It is the first Polish study that set these goals in a nationwide sample of primary care physicians, cardiologists, and diabetologists in Poland. The recent study by Kłosiewicz-Latoszek et al. [15] only evaluated adherence to the European Society of Cardiology/European Atherosclerosis Society (ESC/EAS) guidelines [8] in patients with a previous appropriate diagnosis of $\mathrm{FH}$, who were cared for by physicians in a single specialist clinic. Thus, the ability to diagnose $\mathrm{FH}$ by the participating physicians cannot be compared between our study and the study 
by Kłosiewicz-Latoszek et al. [15]. In addition, the authors of the latter study work in a specialist lipid disorder clinic and thus are experts in this area.

Our findings regarding the appropriateness of the diagnosis of $\mathrm{FH}$ are disturbing. When extrapolated to the overall outpatient population in Poland, the diagnosis of $\mathrm{FH}$ would be confirmed based on the DLCN criteria in 34,000 of 88,000 patients with the diagnosis of $\mathrm{FH}$ declared by the participating physicians, and it would not be confirmed by the DLCN criteria in the remaining patients. In contrast, among patients without the diagnosis of $\mathrm{FH}$ by the participating physicians, extrapolated to 3,349,035 outpatients nationwide, $\mathrm{FH}$ might be diagnosed by the DLCN criteria in 90,400 patients. Finally, $\mathrm{FH}$ might be diagnosed by the DLCN criteria in 11,500 of the estimated 320,000 patients nationwide in whom the participating physicians declared a lack of data to diagnose or exclude FH. In summary, FH might be diagnosed in 136,000 adult outpatients in Poland, and the extrapolated number of appropriate diagnoses of $\mathrm{FH}$ by the participating physicians $(34,000)$ is only $25 \%$ of the overall number of patients with $\mathrm{FH}(136,300)$. This gives 102,000 patients (75\%) with $\mathrm{FH}$ who remain without the proper diagnosis. These data indicate that physicians have inadequate knowledge regarding the diagnosis of $\mathrm{FH}$.

In addition, our findings indicate that drug treatment in these patients is also inadequate. Despite the high LDL-C levels that always accompany $\mathrm{FH}$, as many as $45.1 \%$ of patients were prescribed with low statin doses during a study visit, including $56.2 \%$ of patients treated by primary care physicians and $15.2 \%$ of patients treated by cardiologists. High statin doses were prescribed to $32.8 \%$ patients. Thus, the potential benefits of statin therapy were not utilised adequately in the treatment of $\mathrm{FH}$.

Our study also indicates that even in patients treated with high statin doses, high LDL-C levels of $\geq 4.1 \mathrm{mmol} / \mathrm{L}$ and $\geq 4.9 \mathrm{mmol} / \mathrm{L}$ were noted in $59.7 \%$ and $42.7 \%$ of patients, respectively. The ESC/EAS guidelines recommend lowering $\mathrm{LDL}-\mathrm{C}$ level to $<2.6 \mathrm{mmol} / \mathrm{L}$ in subjects without cardiovascular disease and $<1.8 \mathrm{mmol} / \mathrm{L}$ in subjects with cardiovascular disease [8]. In our study, $88.3 \%$ of patients with $\mathrm{FH}$, who received high statin doses, had a LDL-C level $\geq 2.6 \mathrm{mmol} / \mathrm{L}$. This proportion is much higher compared to the proportion of Polish patients with coronary artery disease with high LDL-C (9\% with $\mathrm{LDL}-\mathrm{C} \geq 4.0 \mathrm{mmol} / \mathrm{L}$ and $30 \%$ with $\mathrm{LDL}-\mathrm{C} \geq 4.0 \mathrm{mmol} / \mathrm{L}$ ) despite high-dose statin treatment [16].

The target LDL-C level in patients with $\mathrm{FH}$ and cardiovascular disease is $<1.8 \mathrm{mmol} / \mathrm{L}$ [8]. Our study provided no data on the proportion of patients who achieved target LDL-C levels. However, among secondary prevention patients with $\mathrm{FH}$, LDL-C level was $\geq 2.6 \mathrm{mmol} / \mathrm{L}$ in $85.7 \%$ of patients, $\geq 4.9 \mathrm{mmol} / \mathrm{L}$ in $43.6 \%$ of patients, and $\geq 4.1 \mathrm{mmol} / \mathrm{L}$ in $52.5 \%$ of patients. These proportions may be extrapolated to large patient numbers nationwide, as indicated in the results
In the abovementioned retrospective study by Kłosiewicz-Latoszek et al. [15], which evaluated patients in a specialist clinic, more than half (56.9\%) of 222 patients with $\mathrm{FH}$ were treated with high statin doses, $39.7 \%$ received moderate statin doses, and $7 \%$ received low statin doses. Target LDL-C level $(<1.8 \mathrm{mmol} / \mathrm{L}$ or $<2.6 \mathrm{mmol} / \mathrm{L}$, depending on the risk level) was achieved by $25.2 \%$ of patients, regardless of the therapy used, including $13.3 \%$ of the high-risk patients. These data suggest, as might be expected, that treatment of $\mathrm{FH}$ in a specialist lipid disorder clinic is superior to regular outpatient care in Poland, as indicated by higher proportions of patients receiving high statin doses $(56.9 \%$ vs. $32.8 \%)$ or combined statin and ezetimibe therapy (44.6\% vs. $7.4 \%$ ). However, even specialist clinic treatment cannot be considered optimal because only $25.2 \%$ of patients achieved target LDL-C levels. Undertreatment is also an unresolved problem in countries such the Netherlands, where only $21 \%$ of $\mathrm{FH}$ patients reached LDL-C level $<2.5 \mathrm{mmol} / \mathrm{L}$ [17]. This indicates the need for novel therapeutic options in some patients.

Our study findings indicate that the diagnosis and treatment of FH in Poland is suboptimal. Only a small proportion of patients received intensive statin therapy or combined therapy. The reasons for this are complex and include unawareness of a high prevalence of $\mathrm{FH}$ and a high cardiovascular risk associated with $\mathrm{FH}$, in particular coronary risk, low awareness and use of the DLCN diagnostic criteria, not using cascade screening to identify affected patient family members, low use of available therapeutic options, and unavailability of new therapeutic options (PCSK9 inhibitors) that allow target LDL-C levels to be achieved when added to a therapy with a maximum tolerated statin dose plus ezetimibe. Such an approach to the treatment of FH has been recommended in the ESC/EAS Consensus Paper [18] and in the updated National Lipid Association guidelines directed for outpatient care [10]. This is justified by observations of lower coronary event rates following LDL-C level reduction in $\mathrm{FH}$ patients treated with statins compared to the pre-statin era $[19,20]$. New therapeutic options may further improve treatment outcomes for this condition.

Our research, by assumption, does not include patients who do not use outpatient care, particularly those who do not take advice from general practitioners, cardiologists, and diabetologists. Detailed data regarding the applied therapy and patients' condition was not collected in reference to patients in whom recently noted LDL-C concentration was $1.8 \mathrm{mmol} / \mathrm{L}$ or lower. Moreover, some limitations result from the sampling method and the manner of data collection: when inviting physicians for the study a quota sampling was applied due to the lack of effective use of random sampling. Data regarding the use of treatment and patients' medical profile was obtained based on physicians' declarations (the basis for which was data from patients' medical records) and it was not additionally objectively verified. 
In conclusion: (1) Based on extrapolation of our study findings, it may be estimated that at least probable $\mathrm{FH}$ (score $6+$ by the DLCN criteria) may be present in 136,300 adult outpatients in Poland with LDL-C levels $>1.8 \mathrm{mmol} / \mathrm{L}$. This would mean that a relatively large population of Polish patients still awaits proper diagnosis, prevention, and treatment. (2) Among diagnoses of $\mathrm{FH}$ declared by the study physicians (88,000 cases nationwide), only 39\% could be confirmed by the DLCN criteria. Among patients with the diagnosis of $\mathrm{FH} 6+$ based on the DLCN criteria, the diagnosis of $\mathrm{FH}$ was appropriately made in only $25 \%$ of cases, and $75 \%$ of cases remained undiagnosed despite clinical evidence that would allow this diagnosis. The latter translates to about 102,000 patients receiving outpatient care from primary care physicians, cardiologists, and diabetologists. These findings indicate a need to educate physicians about the diagnostic criteria and the diagnosis of FH. (3) Only $32.8 \%$ of patients with $\mathrm{FH}$ - after weighting and extrapolation — receive high statin doses, and LDL-C levels are $\geq 5.0 \mathrm{mmol} / \mathrm{L}$ in as many as $42.7 \%$, and $\geq 4.1 \mathrm{mmol} / \mathrm{L}$ in $59.7 \%$ of those treated with high statin doses. These findings reflect a low level of adherence to the recommendations regarding treatment of patients with $\mathrm{FH}$.

\section{Conflict of interest: none declared}

\section{References}

1. Pajak A, Szafraniec K, Polak M, et al. Prevalence of familial hypercholesterolemia: a meta-analysis of six large, observational, population-based studies in Poland. Arch Med Sci. 2016; 12(4): 687-696, doi: 10.5114/aoms.2016.59700, indexed in Pubmed: 27478447.

2. Rynkiewicz A, Cybulska B, Banach M, et al. Postępowanie w heterozygotycznej hipercholesterolemii rodzinnej. Stanowisko Forum Ekspertów Lipidowych. Kardiol Pol. 2013; 71(1): 107-111, indexed in Pubmed: 23348551.

3. Nordestgaard BG, Chapman MI, Humphries SE, et al. European Atherosclerosis Society Consensus Panel. Familial hypercholesterolaemia is underdiagnosed and undertreated in the general population: guidance for clinicians to prevent coronary heart disease: consensus statement of the European Atherosclerosis Society. Eur Heart J. 2013; 34(45): 3478-90a, doi: 10.1093/eurhearti/eht273, indexed in Pubmed: 23956253.

4. Kastelein JJP, Ginsberg HN, Langslet G, et al. ODYSSEY FH I and FH II: 78 week results with alirocumab treatment in 735 patients with heterozygous familial hypercholesterolaemia. Eur Heart J. 2015; 36(43): 2996-3003, doi: 10.1093/eurheartj/ehv370, indexed in Pubmed: 26330422

5. Ginsberg HN, Rader DJ, Raal FJ, et al. Efficacy and Safety of Alirocumab in Patients with Heterozygous Familial Hypercholesterolemia and LDL-C of $160 \mathrm{mg} / \mathrm{dl}$ or Higher. Cardiovasc Drugs Ther. 2016; 30(5): 473-483, doi: 10.1007/s10557-016-6685-y, indexed in Pubmed: 27618825.

6. Raal FJ, Stein EA, Dufour R, et al. RUTHERFORD-2 Investigators. PCSK9 inhibition with evolocumab (AMG 145) in heterozygous familial hypercholesterolaemia (RUTHERFORD-2): a randomised, double-blind, placebo-controlled trial. Lancet. 2015; 385(9965): 331-340, doi: 10.1016/S0140-6736(14)61399-4, indexed in Pubmed: 25282519.

7. Gidding SS, Champagne MA, de Ferranti SD, et al. American Heart Association Atherosclerosis, Hypertension, and Obesity in Young Committee of Council on Cardiovascular Disease in Young, Council on Cardiovascular and Stroke Nursing, Council on Functional Genomics and Translational Biology, and Council on Lifestyle and Cardiometabolic Health. The Agenda for Familial Hypercholesterolemia: A Scientific Statement From the American Heart Association. Circulation. 2015; 132(22): 2167-2192, doi: 10.1161/CIR.0000000000000297, indexed in Pubmed: 26510694.

8. Catapano AL, Graham I, De Backer G, et al. ESC Scientific Document Group. 2016 ESC/EAS Guidelines for the Management of Dyslipidaemias. Eur Heart J. 2016; 37(39): 2999-3058, doi: 10.1093/eurheartj/ehw272, indexed in Pubmed: 27567407.

9. Santos RD, Gidding SS, Hegele RA, et al. International Atherosclerosis Society Severe Familial Hypercholesterolemia Panel. Defining severe familial hypercholesterolaemia and the implications for clinical management: a consensus statement from the International Atherosclerosis Society Severe Familial Hypercholesterolemia Panel. Lancet Diabetes Endocrinol. 2016; 4(10): 850-861, doi: 10.1016/S2213-8587(16)30041-9, indexed in Pubmed: 27246162.

10. Orringer CE, Jacobson TA, Saseen JJ, et al. Update on the use of PCSK9 inhibitors in adults: Recommendations from an Expert Panel of the National Lipid Association. J Clin Lipidol. 2017; 11(4): 880-890, doi: 10.1016/j.jacl.2017.05.001, indexed in Pubmed: 28532784

11. Benn M, Watts GF, Tybjærg-Hansen A, et al. Mutations causative of familial hypercholesterolaemia: screening of 98098 individuals from the Copenhagen General Population Study estimated a prevalence of 1 in 217. Eur Heart J. 2016; 37(17): 1384-1394, doi: 10.1093/eurheartj/ehw028, indexed in Pubmed: 26908947.

12. Zamora A, Masana L, Comas-Cufí M, et al. XULA and ISV-Girona groups. Familial hypercholesterolemia in a European Mediterranean population-Prevalence and clinical data from 2.5 million primary care patients. J Clin Lipidol. 2017; 11(4): 1013-1022, doi: 10.1016/j.jacl.2017.05.012, indexed in Pubmed: 28826564.

13. Leren TP, Manshaus T, Skovholt U, et al. Application of molecular genetics for diagnosing familial hypercholesterolemia in Norway: results from a family-based screening program. Semin Vasc Med. 2004; 4(1): 75-85, doi: 10.1055/s-2004-822989, indexed in Pubmed: 15199436.

14. De Backer G, Besseling J, Chapman J, et al. EUROASPIRE Investigators. Prevalence and management of familial hypercholesterolaemia in coronary patients: An analysis of EUROASPIRE IV, a study of the European Society of Cardiology. Atherosclerosis. 2015; 241(1): 169-175, doi: 10.1016/j.atherosclerosis.2015.04.809, indexed in Pubmed: 25997074.

15. Kłosiewicz-Latoszek L, Cybulska B, Białobrzeska-Paluszkiewicz J, et al. Clinical management of heterozygous familial hypercholesterolaemia in Polish outpatient metabolic clinic. Arch Med Sci. 2017(w druku), doi: 10.5603/KP.a2018.0053.

16. Jankowski P, Czarnecka D, Łukaszewska A, et al. Factors related to the effectiveness of hypercholesterolemia treatment following hospitalization for coronary artery disease. Pol Arch Med Wewn. 2016; 126(6): 388-394, doi: 10.20452/pamw.3447, indexed in Pubmed: 27362391.

17. Pijlman AH, Huijgen R, Verhagen SN, et al. Evaluation of cholesterol lowering treatment of patients with familial hypercholesterolemia: a large cross-sectional study in The Netherlands. Atherosclerosis. 2010; 209(1): 189-194, doi: 10.1016/j. atherosclerosis.2009.09.014, indexed in Pubmed: 19818960.

18. Landmesser U, Chapman MJ, Stock JK, et al. 2017 Update of ESC/EAS Task Force on practical clinical guidance for proprotein convertase subtilisin/kexin type 9 inhibition in patients with atherosclerotic cardiovascular disease or in familial hypercholesterolaemia. Eur Heart J. 2017 [Epub ahead of print], doi: 10.1093/eurheartj/ehx549, indexed in Pubmed: 29045644.

19. Versmissen J, Oosterveer DM, Yazdanpanah M, et al. Efficacy of statins in familial hypercholesterolaemia: a long term cohort study. BMJ. 2008; 337: a2423, doi: 10.1136/bmj.a2423, indexed in Pubmed: 19001495.

20. Besseling J, Hovingh GK, Huijgen R, et al Statins in Familial Hypercholesterolemia: Consequences for Coronary Artery Disease and All-Cause Mortality. J Am Coll Cardiol. 2016; 68(3): 252-260, doi: 10.1016/j.jacc.2016.04.054, indexed in Pubmed: 27417002.

Cite this article as: Chlebus K, Cybulska B, Gruchała M, et al. Prevalence, diagnosis, and treatment of familial hypercholesterolaemia in outpatient practices in Poland. Kardiol Pol. 2018; 76(6): 960-967, doi: 10.5603/KP.a2018.0053. 